\title{
Stability and Volumetric Properties of Asphalt Mixture Containing Waste Plastic
}

\author{
Siti Aminah Abd Kader ${ }^{1}$, Ramadhansyah Putra Jaya ${ }^{2,3,}$, , Haryati Yaacob ${ }^{4}$, Mohd Rosli \\ Hainin $^{5}$, Norhidayah Abdul Hassan ${ }^{6}$, Mohd Haziman Wan Ibrahim ${ }^{7}$, Abdullahi Ali \\ Mohamed $^{8}$, and Ichwana ${ }^{9}$ \\ 1,2,4,5,6 Faculty of Civil Engineering, Department of Geotechnics and Transportation, Universiti \\ Teknologi Malaysia, 81310 UTM Skudai, Johor Bahru, Malaysia \\ ${ }^{3}$ Faculty of Engineering, Department of Civil and Environmental Engineering, Universiti Teknologi \\ PETRONAS, 32610 Seri Iskandar, Perak Darul Ridzuan, Malaysia \\ ${ }^{7}$ Faculty of Civil and Environmental Engineering, Universiti Tun Hussein Onn Malaysia, 86400 Batu \\ Pahat, Johor, Malaysia \\ ${ }^{8}$ Faculty of Engineering, The University of Nottingham Malaysia Campus, Jalan Broga, 43500 \\ Semenyih, Selangor Darul Ehsan, Malaysia \\ ${ }^{9}$ Faculty of Agriculture, Department of Agricultural Engineering, Universitas Syiah Kuala, 23111 \\ Darussalam, Banda Aceh, Indonesia
}

\begin{abstract}
The objectives of this study are to determine the optimum bitumen content $(\mathrm{OBC})$ for every percentage added of waste plastics in asphalt mixtures and to investigate the stability properties of the asphalt mixtures containing waste plastic. Marshall stability and flow values along with density, air voids in total mix, voids in mineral aggregate, and voids filled with bitumen were determined to obtain OBC at different percentages of waste plastic, i.e., $4 \%, 6 \%, 8 \%$, and $10 \%$ by weight of bitumen as additive. Results showed that the OBC for the plastic-modified asphalt mixtures at $4 \%, 6 \%, 8 \%$, and $10 \%$ are $4.98,5.44,5.48$, and 5.14 , respectively. On the other hand, the controlled specimen's shows better volumetric properties compared to plastic mixes. However, $4 \%$ additional of waste plastic indicated better stability than controlled specimen.
\end{abstract}

\section{Introduction}

Plastic is used regularly in today's lifestyle, and its disposal is a great problem [1]. Plastic is a non-biodegradable product; thus, it causes environmental pollution and problems [2]. The issue now is to reduce plastic waste by transforming it into something beneficial. Given that the plastics used in PET bottles, disposal glasses, handbags, and covers of various appliances soften up at $160^{\circ} \mathrm{C}$ [3], a solution is to use waste plastic in such a manner that it gets coated over by an aggregate via heating $\left(140-160^{\circ} \mathrm{C}\right)$ [4]. Asphalt mixtures, commonly called asphalt concrete in the United States, are composite materials commonly used in surface roads, parking lots, and airports. Asphalt concrete consists of aggregate and asphalt/bitumen laid in layers and then compacted. Bitumen acts as binder to bind the

*Corresponding author: ramadhansyah@utm.my 
aggregates together. One of the main problems of polyethylene is that without special treatment it is not readily biodegradable and thus accumulates. Over 500 billion to 1 trillion plastic bags are consumed worldwide. Plastic waste is a serious problem that can lead to many other problems [5]. A recent study had found one more way to reduce the amount of plastic waste by using it in asphalt mixtures [6]. Waste plastic bags can be used as a modifier of hot-mix asphalt [7]. Costa et al. [8] reported that utilization of waste plastic in flexible pavement has been established since 2012. A study was carried out by using plastic waste of $0 \%-12 \%$ by weight of bitumen. As a result, the stability, strength, fatigue life, and other characteristics of the asphalt mixture were improved even under adverse waterlogging conditions. Kumar and Garg [9] recycled waste plastics bags in bituminous mix by using $1.2-3 \mathrm{~mm}$ particle size. They found that the stability and flow were improved. It can be concluded that the added waste plastic can strongly improve the binder properties, provide safer road, and reduce the maintenance cost by increasing the stiffness of the bitumen and by improving its temperature susceptibility. The process is environment friendly. Thus, these processes are socially highly relevant and give better infrastructure.

\section{Materials and experimental procedures}

\subsection{Raw materials preparation}

The binder used in this study is bitumen 60/70. Bitumen were heated in the oven till fluid conditions, then plastic were prepared to be added gradually to the bitumen and blended for three to five minutes. Mixing was continued for a certain time to produce homogenous mixtures. Three specimens were prepared for each percentage of plastic. After Specimens have been compacted using Marshall Hammer, then were tested for stability, flow, VTM, VMA, and VFB. Furthermore, granite aggregates used in this investigation is nearly always massive, hard and. The gradation test (Fig. 1) was conducted following the procedure outlined in BS EN [10] and JKR [11].

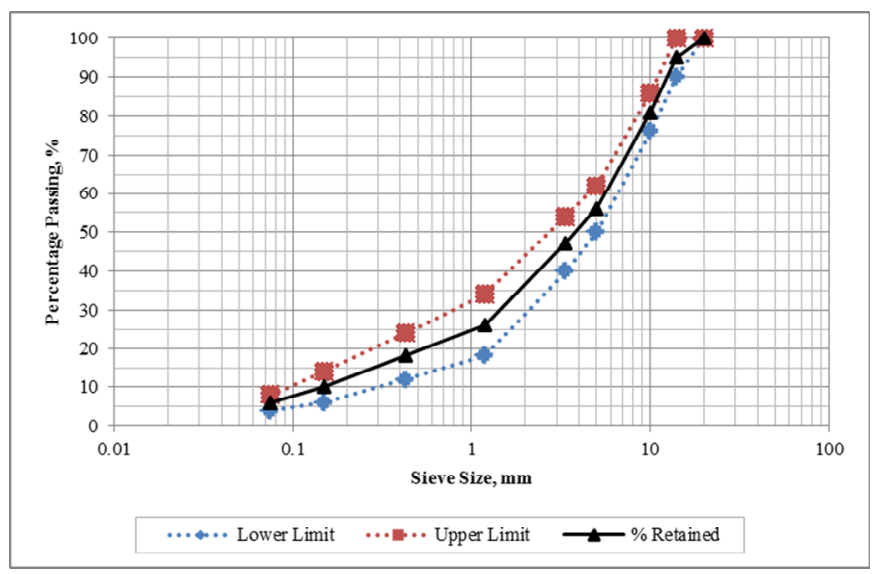

Fig. 1. Aggregate gradation of asphalt mix [11]

\subsection{Marshall mix design}

In the laboratory, the aggregate, binder and plastic were respectively mixed and compacted at $180 \pm 0.5^{\circ} \mathrm{C}$. The mixes were compacted with 75 blows on each side with the standard 
Marshall hammer to avoid disintegration of materials. After compaction, the specimens were removed from the molds and allowed to cool down.

\subsection{Stability test}

The stability value of each test specimen shall then be determined in accordance with BS EN [12]. In the stability test, the specimens were prepared with the specified temperature by immersing in a water bath at a temperature of $60^{\circ} \mathrm{C} \pm 1^{\circ} \mathrm{C}$ for a period of 45 minutes. It was then placed in the Marshall Stability testing machine and loaded at a constant rate of deformation of $50.8 \mathrm{~mm} /$ minute until the maximum load was reached.

\section{Result and discussion}

\subsection{OBC determination}

According to Ramadhansyah et al. [13], the OBC of the controlled sample (AC14) is $5.1 \%$. However, the $\mathrm{OBC}$ values for $4 \%, 6 \%, 8 \%$, and $10 \%$ plastic added are shown in Table 1 . The OBC increases for $4 \%, 6 \%$, and $8 \%$ and then decreases for $10 \%$. OBC has a relationship with the stability value. Stability value also increases up to a certain amount of plastic added, and further addition of plastic beyond this limit decreases the stability.

Table 1. OBC at different percentage plastic

\begin{tabular}{cc}
\hline \% Plastic & OBC \\
\hline 4.0 & 4.98 \\
6.0 & 5.44 \\
8.0 & 5.48 \\
10.0 & 5.14 \\
\hline
\end{tabular}

\subsubsection{Stability}

Fig. 2 shows the relationship between stability and percentage of plastic. The stability of $4 \%$ plastic is the highest (i.e., $184 \mathrm{kN}$ ), and it slightly decreases with the increase of plastic addition. A large gap between the stability of the conventional asphalt mixture and the plastic modified asphaltic concrete is observed (i.e., more than 100\%). Stability verifies the performance of the asphalt mixture under loading. The results showed that plastic can increase the stability of the asphalt mixture up to certain percentages and after that it will decrease.

\subsubsection{Flow}

Fig. 3 shows the effects of flow with different percentage of plastic in asphalt mixture. Flow is related to stability and shows the flexibility of the mix. Flow for the conventional asphalt mixture is $2.85 \mathrm{~mm}$ [14], which is the lowest. Flow of the modified asphalt mixture is higher than the flow of the conventional asphalt mixture. The difference between the modified and conventional asphalt mixture varies from $19 \%$ to $37 \%$. The highest flow is $3.9 \mathrm{~mm}$, which is when $10 \%$ plastic was added. 


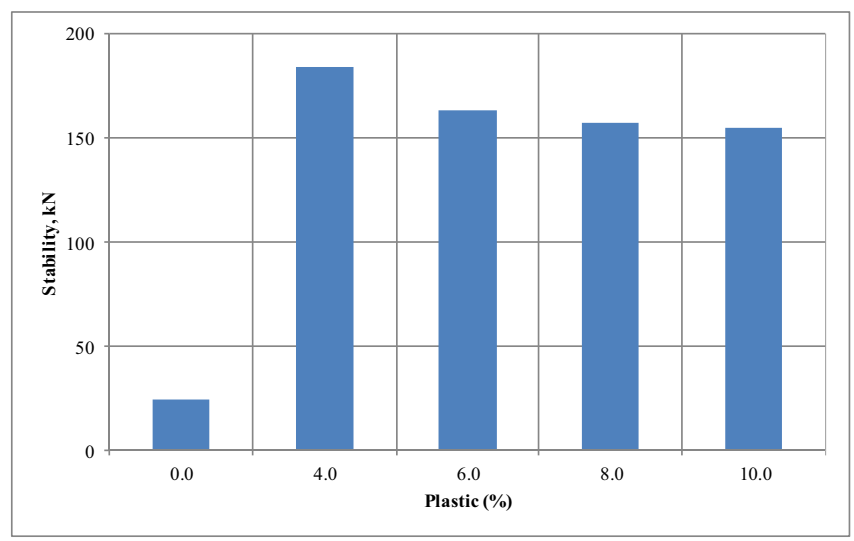

Fig. 2. Stability of asphalt mixture at different percentage plastic

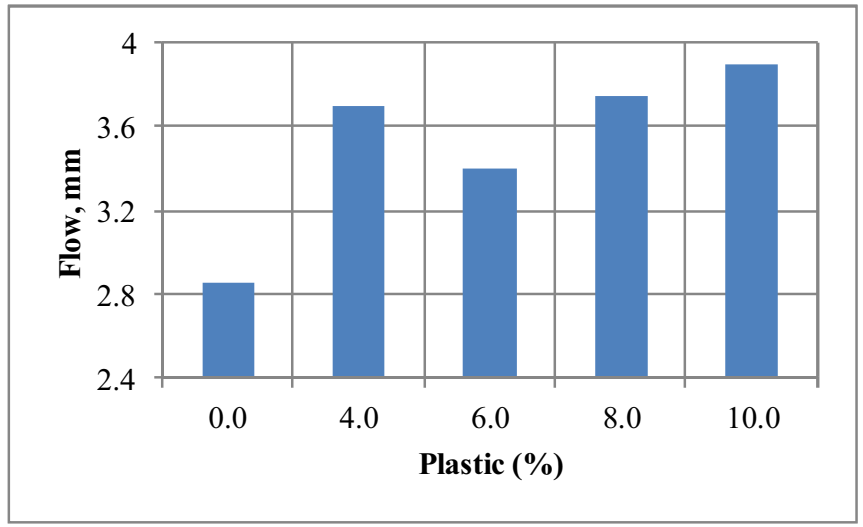

Fig. 3. Flow of asphalt mixture at different percentage plastic

\subsubsection{Stiffness}

Fig. 4 shows the effect of different percentage of plastic to the stiffness. The stiffness of the modified asphalt mixture increases (4\% and 6\%) but decreases for $8 \%$ and $10 \%$. Therefore, plastic can increase the stiffness of the asphalt mixture up to certain percentages and then decrease after it reaches the optimum value. The conventional asphalt mixture has the lowest stiffness, that is, $8.53 \mathrm{kN} / \mathrm{mm}$. Stiffness is an important parameter to measure the rutting. A higher stiffness pavement is good. However, a too high stiffness can lead to fatigue cracking [15].

\subsection{Volumetric properties}

The volumetric properties are reflected on the volume of bitumen and aggregates required to produce a mixture of desired properties. Mixture volumetric properties are important for long-term performance and durability of pavements. 


\subsubsection{Density}

Density is the mass per unit volume. The densities of asphalt mixture at different percentage of plastic are shown in Fig. 5. The density of the asphalt mixture decreases with the increase of percentage plastic. Conventional asphalt mixture has density of $2.349 \mathrm{~g} / \mathrm{cm}^{3}$. Plastic-modified asphalt mixture with $4 \%$ plastic has the highest density, that is, 2.500 $\mathrm{g} / \mathrm{cm}^{3}$, which is $6 \%$ higher than the conventional asphalt. As the percentages of plastic increase, the volume of the asphalt mixture increased. Therefore, the density decreased.

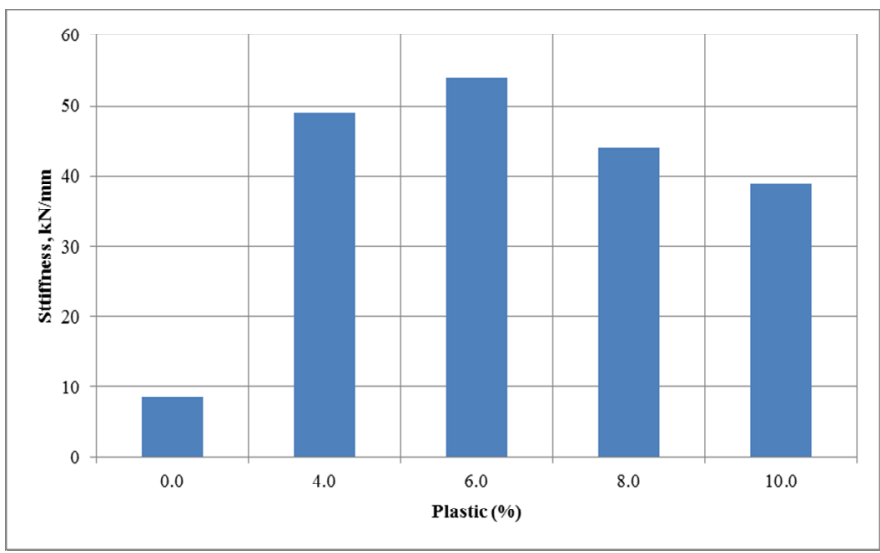

Fig. 4. Stiffness of asphalt mixture at different percentage plastic

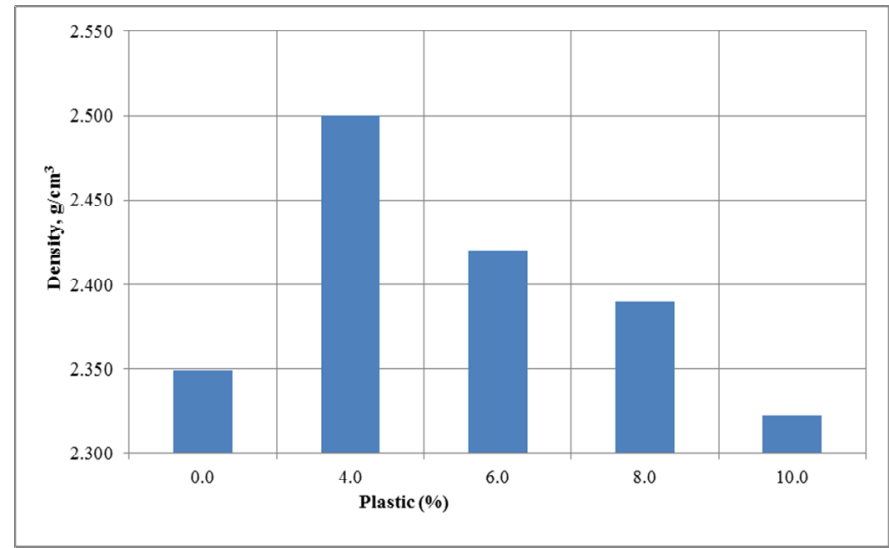

Fig. 5. Density of asphalt mixture at different percentage plastic

\subsubsection{Voids in Total Mix}

Fig. 6 shows the effect of plastic added on voids in total mix. The VTM of the conventional asphalt mixture is $3.6 \%$, whereas the VTM of the plastic-modified asphalt mixture varies from $4.0 \%$ to $7.0 \%$. According to JKR [11], the range of VTM is from 3\% to 5\%. Based on the result presented in the figure, the VTM values for $4 \%$ and $8 \%$ plastic are out of range, whereas the VTM for $6 \%$ and $10 \%$ plastic are in the range. VTM is also known as air voids and is the ratio of the volume of voids in a compacted mixture to the total compacted mixture volume. Voids can be reduced by conducting compaction properly. The compactor 
machine needs to be maintained regularly to make sure that it works well during the compaction process.

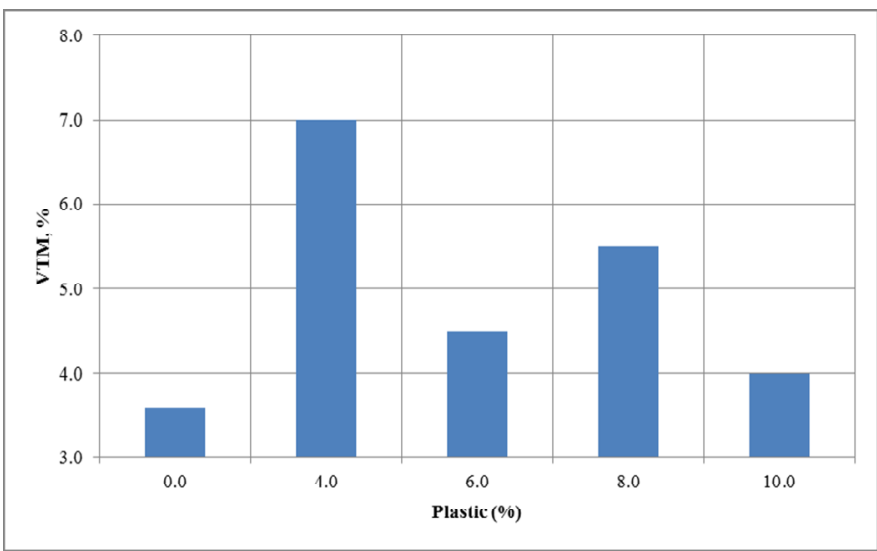

Fig. 6. VTM of asphalt mixture at different percentage plastic

\subsubsection{Voids Filled with Bitumen}

The voids filled with bitumen (VFA) are plotted against the percentage of plastic addition in Fig. 7. Voids filled with asphalt binder is the percent of voids in mineral aggregate (VMA) that is filled with asphalt cement. VFA for the conventional asphalt mixture is $76 \%$, and it is quite similar to VFA for $10 \%$ plastic, that is, $73 \%$. VFA for $4 \%$ plastic is the highest (i.e., 140\%). The VFA for $6 \%$ and $8 \%$ are constant (i.e., $97 \%$ and $95 \%$, respectively), but still out of range of the JKR [11] specification that is in between $70 \%$ to $80 \%$.

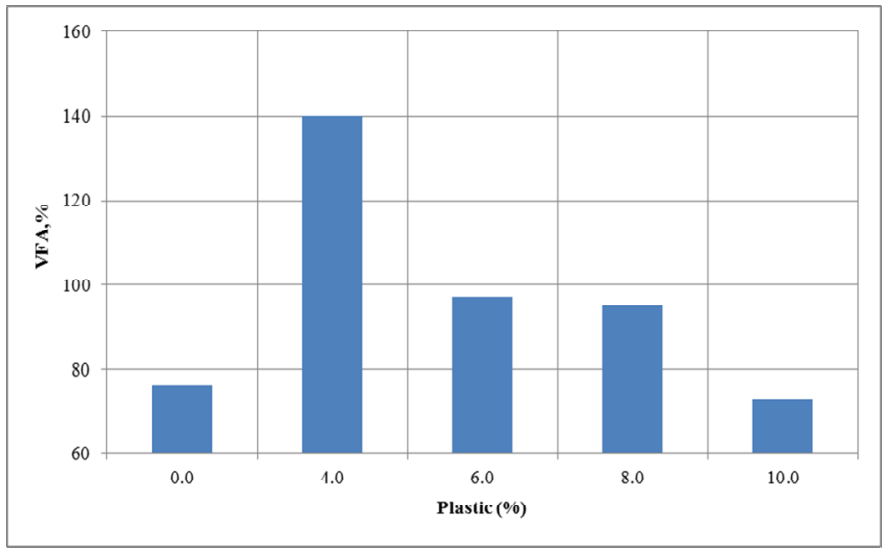

Fig. 7. VTM of asphalt mixture at different percentage plastic

\section{Conclusion}

Based on the result and analysis, it can be seen that the OBC of asphalt mixture containing waste plastic increases $(4 \%-8 \%)$ and then decreases at $10 \%$ added. In comparison between plastic percentage levels, $4 \%$ waste plastic showed excellent stability. Furthermore, the 
results revealed that controlled specimen's shows better volumetric properties compared to waste plastic mixes. However, $4 \%$ added of waste plastic indicated better performance than controlled specimen.

The support provided by Malaysian Ministry of Higher Education (MOHE) and Universiti Teknologi Malaysia (UTM) in the form of a research grant number Q.J130000.2522.11H58 for this study is very much appreciated.

\section{References}

[1] E.A. Asamany, M.D. Gibson, M.J. Pegg, Evaluating the potential of waste plastics as fuel in cement kilns using bench-scale emissions analysis, Fuel, 193(1), 178-186 (2017)

[2] T. Sri Devi Kumari, A.J.J. Jebaraj, T.A. Raj, D. Jeyakumar, T.P. Kumar, A kish graphitic lithium-insertion anode material obtained from non-biodegradable plastic waste, Energy, 95, 483-493 (2016)

[3] B.T. Ashwini Manjunath, Partial replacement of e-plastic waste as coarse-aggregate in concrete, Procedia Environmental Sciences, 35, 731-739 (2016)

[4] M. Naskar, T.K. Chaki, K.S. Reddy, Effect of waste plastic as modifier on thermal stability and degradation kinetics of bitumen/waste plastics blend, Thermochimica Acta, 509(1-2), 128-134 (2010)

[5] S. Köfteci, P. Ahmedzade, B. Kultayev, Performance evaluation of bitumen modified by various types of waste plastics, Construction and Building Materials, 73, 592-602 (2014)

[6] Johnson Kwabena Appiah, Victor Nana Berko-Boateng, Trinity Ama Tagbor, Use of waste plastic materials for road construction in Ghana, Case Studies in Construction Materials, 6, 1-7 (2017)

[7] M. Garcia-Morales, P. Partal, F.J. Navarro, C. Gallegos, Effect of waste polymer addition on the rheology of modified bitumen, Fuel, 85, 936-943 (2006)

[8] L.M.B. Costa, H.M.R.D. Silva, J.R.M. Oliveiran, S.R.M. Fernandes, Incorporation of waste plastic in asphalt binders to improve their performance in the pavement, Int. J. Pavement Research and Technology, 6(4), 457-464 (2013)

[9] P. Kumar, R. Garg, Rheology of waste plastic fibre-modified bitumen, Int. J. Pavement Engineering, 12(5), 449-459 (2011)

[10] BS EN 933-1:2012, Tests for geometrical properties of aggregates. Determination of particle size distribution, sieving method, BSI, London, (2012)

[11] JKR/SPJ/2008-S4, Standard specification for road works, Malaysian Public Works Department, Kuala Lumpur, (2008)

[12] BS EN 12697-34:2012, Bituminous mixtures. Test methods for hot mix asphalt. Marshall test, BSI, London, (2012)

[13] P.J. Ramadhansyah, M. Nurfatin Aqeela, J. Siti Nur Amiera, M. Norhafizah, A.H. Norhidayah, S.J. Dewi, Use of coconut shell from agriculture waste as fine aggregate in asphaltic concrete, ARPN J. Engineering and Applied Sciences, 11(12), 7457-7462 (2016)

[14] M. Norhafizah, P.J. Ramadhansyah, J. Siti Nur Amiera, M. Nurfatin Aqeela, A.H. Norhidayah, M.R. Hainin, C.W. Che Norazman, The effect of coconut shell on engineering properties of porous asphalt mixture, J. Teknologi, 78(7-2), 127-132 (2016)

[15] S.N.A. Jeffry, R.P. Jaya, N. Manap, N.A. Miron, N.A. Hassan, The influence of coconut shell as coarse aggregates in asphalt mixture, Key Engineering Materials, 700, 227-237 (2016) 